\title{
Horton's disease: still an important medical problem in elderly patients: a review and case report
}

\author{
Krzysztof Gomułka', Joanna Radzik-Zając ${ }^{1}$, Urszula Zaleska-Dorobisz² ${ }^{2}$ Bernard Panaszek ${ }^{1}$
}

${ }^{1}$ Department of Internal Medicine and Allergology, Wroclaw Medical University, Wroclaw, Poland

${ }^{2}$ Department of General and Pediatric Radiology, Wroclaw Medical University, Wroclaw, Poland

Adv Dermatol Allergol 2017; XXXIV (5): 510-513

DOI: https://doi.org/10.5114/ada.2017.71124

Giant-cell arteritis (GCA) is a systemic inflammatory vasculitis of unknown etiology commonly involving large and medium-sized arteries of the head (cranial arteritis). Horton's disease is a clinical entity caused by GCA mainly of temporal arteries (temporal arteritis). It is the most common form of systemic vasculitis in adults and elderly persons (arteritis of the aged) and can be an important medical problem resulting in a wide variety of systemic, neurological and ophthalmological complications. Giantcell arteritis typically affects medium- and large-sized vessels including the superficial temporal arteries, the aorta, the carotid, subclavian and iliac arteries. In addition, the ophthalmic, occipital and vertebral arteries may be affected. The mean age of onset is above 55 years, and it is rare in people aged less than 55 years. Risk factors for manifestation of GCA are age and female sex (women to men ratio is $2: 1$ ); also a genetic background and infection may play a role in it $[1,2]$. The most common symptoms of GCA are results of the involvement of the temporal artery and other medium-sized arteries of the head and the neck; these signs may include the headache, jaw and tongue claudication, tenderness and sensitivity on the scalp, neck pain, acute tinnitus and visual disturbances [3]. For this reason GCA should always be considered in the differential diagnosis of a new-onset headache in patients older than 50 years of age or with an elevated erythrocyte sedimentation rate [4, 5]. General manifestations, such as a moderate fever, vertigo, bruits, fatigue and malaise may also be present [4, 5]. In the physical examination of patients with Horton's disease, palpation of the head reveals prominent temporal arteries with or without pulsation, tenderness and redness of the temporal area, and even the signs of ischemia might be seen [6]. Laboratory tests may disclose a raised erythrocyte sedimentation rate, elevated platelets count, alkaline phosphatase and C-reactive protein as inflam- matory markers [7]. Using radiological examination such as the temporal arteries' ultrasound, angio-computed tomography or magnetic resonance imaging might be helpful for non-invasive diagnosis of this disorder [8]. Temporal artery biopsy remains the important standard for diagnosis of this vasculitis. Histopathological changes characteristic for the disease are transmural inflammation of the intima, media and adventitia of affected arteries, as well as infiltration by lymphocytes, macrophages and multinuclear giant cells. Mural hyperplasia may lead to arterial narrowing, resulting in distal ischemia [9-11]. The American College of Rheumatology (ACR) has established criteria for the classification of giant cell arteritis [12]. The presence of three or more out of five criteria (age $\geq 50$ years at disease onset, new onset of localized headache, temporal artery tenderness or decreased temporal artery pulse, ESR $\geq 50 \mathrm{~mm} / \mathrm{h}$ and artery biopsy) is particularly helpful for diagnosing patients especially those with an atypical presentation of giant-cell arteritis and unusual clinical manifestation. Corticosteroids, typically a high dose of prednisone ( $1 \mathrm{mg} / \mathrm{kg} /$ day), are the mainstay of therapy and must be started as soon as possible. Oral steroids are at least as effective as intravenous steroids and their dose reduction may require even 2 or more years because the typical patient with giant-cell arteritis should remain on steroid therapy for approximately 2 years [13]. In steroid-resistant cases, drugs such as cyclosporine, aspirin, azathioprine or methotrexate may be used $[14,15]$. In patients with a severe form of the disease and at high risk of prolonged therapy, adverse events of corticosteroids therapy are often observed. For individualized treatment for this group of patients, blockade of interleukin 6 (tocilizumab) and interleukin 1 (gevokizumab) is being evaluated in clinical trials [16].

A 77-year-old female with co-morbidities (i.e. hypertension, paroxysmal atrial fibrillation, allergic asthma,

Address for correspondence: Krzysztof Gomułka MD, PhD, Department of Internal Medicine and Allergology, Wroclaw Medical University, 66 M. Curie-Skłodowskiej St, 50-369 Wroclaw, Poland, phone: +48 7178425 28, e-mail: kgomulka@wp.pl Received: 21.08.2016, accepted: 18.10.2016. 
chronic renal failure) was admitted to the Department of Internal Medicine and Allergology, Wroclaw Medical University, Poland (hospital case number 4720/14) because of the painful small swellings on the surface of the head associated with the pain of the right ear and a mild headache. From the medical interview, it is known that swellings were initially painless. Then, our patient had the lower incisor on the left side extracted and several days after this dental surgery, she got a fever of $38^{\circ} \mathrm{C}$, the number of small swellings on the scalp increased and additionally swelling in the parotid glands appeared. After the extraction the patient took antibiotics (doxycycline, then azithromycin). This case was consulted by a laryngologist and also the computed tomography of the head was performed - there was no abscess or hematoma, but the middle ear infection was found and treatment with cefuroxime was recommended. Due to the lack of improvement in the general condition, the patient was admitted to our unit. On admission, the physical examination showed multiple, painful, palpable lumps within the scalp, soreness and swelling in the parotid glands, especially on the right side, enlarged submandibular lymph nodes on the right side and in the occipital region. Auscultation of the lungs remained normal vesicular sound, the heart rate was $85 / \mathrm{min}$, and the abdomen was soft and painless. Laboratory tests revealed leukocytosis (white blood cells WBC $11.17 \mathrm{G} / \mathrm{l}$ ), elevated platelets count (PLT $440 \mathrm{G} / \mathrm{l}$ ), mild microcytic anemia (haemoglobin (HGB) $12.3 \mathrm{~g} / \mathrm{dl}$ ), raised erythrocyte sedimentation rate (ESR 65 $\mathrm{mm} / \mathrm{h}$ ), increased concentration of the systemic inflammatory marker (C-reactive protein (CRP) $84.5 \mathrm{mg} / \mathrm{l}$ ), retention of the nitrogen metabolite and reduced renal filtering capacity (creatinine $1.96 \mathrm{mg} / \mathrm{dl}$, estimated glomerular filtration rate (eGFR) $25.63 \mathrm{ml} / \mathrm{min} / 1.73 \mathrm{~m}^{2}$ ). The thyroid hormones were within the normal limits. An assessment of the complement system and C1-esterase inhibitor concentration revealed no abnormalities. Total lgE levels were elevated $(278 \mathrm{IU} / \mathrm{ml})$. Investigations for connective tissue diseases and autoimmune diseases (p-ANCA, c-ANCA, ANA) were all negative and the rheumatoid factor was

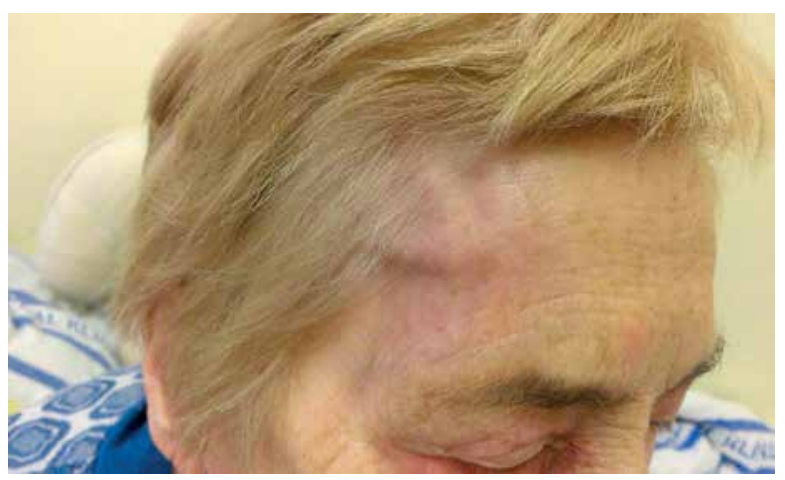

Figure 1 . The patient before treatment - redness and painful swellings in the area of the right temporal artery undetectable. Blood cultures were sterile. The chest $X$-ray, except the small pleural thickening in the left corner near the diaphragm, did not show any changes in the lungs. During the abdominal ultrasound examination, fatty liver and stones in the gallbladder were diagnosed. On the third day of hospitalization, there was observed a significant thickening in the course of the right temporal artery, redness of the skin in this area. Palpable and painful nodules in the course of that artery was seen and associated with the pain of all the facial skeleton, particularly around the lumps (Figure 1). The ultrasound flow in the vertebral and carotid arteries was correct and did not show the presence of atherosclerotic and inflammatory lesions inside. Therefore, taking into account the information obtained from the clinical presentation and the overall diagnostic studies, the diagnosis of Horton's disease was established. In treatment, a high dose of corticosteroids (methylprednisolone) was administered, what gave relief of inflammation and diminished tumors of the temporal artery on the head and pain relief within a few days (Figure 2). After the symptoms have been alleviated the results of the blood tests changed as follows: WBC 13.62 G/l, PLT 265 G/l, HGB 13.6 g/dl, ESR 38 mm/h, CRP $0.8 \mathrm{mg} / \mathrm{l}$, creatinine $1.73 \mathrm{mg} / \mathrm{dl}$, eGFR $28.56 \mathrm{ml}$ $\mathrm{min} / 1.73 \mathrm{~m}^{2}$. In the angio-computed tomography of the head, except for bilateral calcification in traps of the internal carotid artery, venous sinus hypoplasia of the left and a small thrombus in the right lateral bay, there were no other lesions, especially artery wall sickness and narrowing of the artery diameter (Figures 3 A, B).

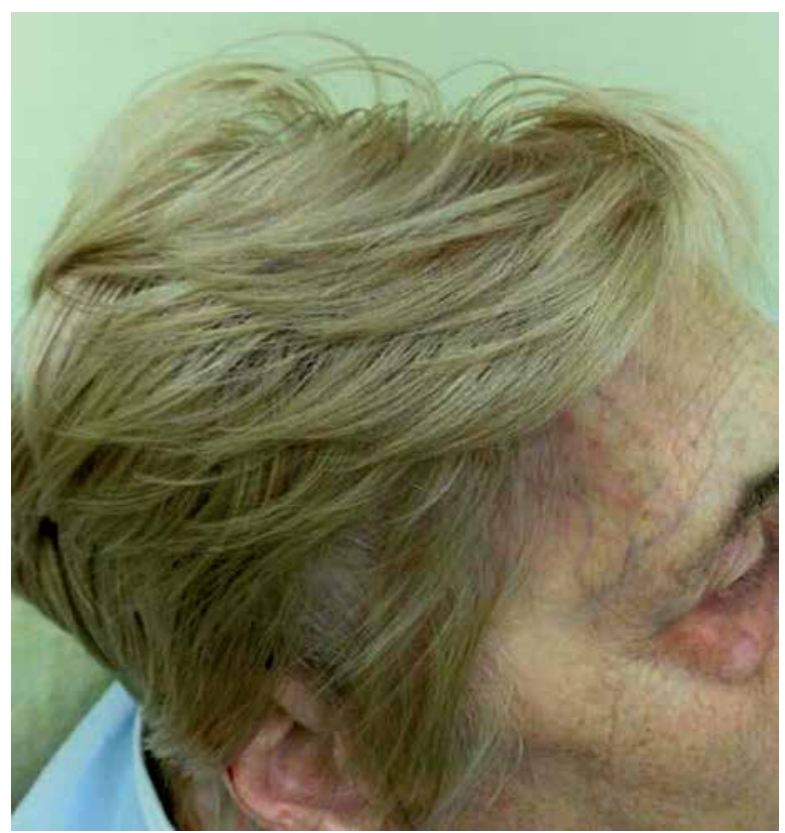

Figure 2. The patient a few days after introducing corticosteroids (methylprednisolone) - reduction of swellings of the temporal artery and redness of its area 

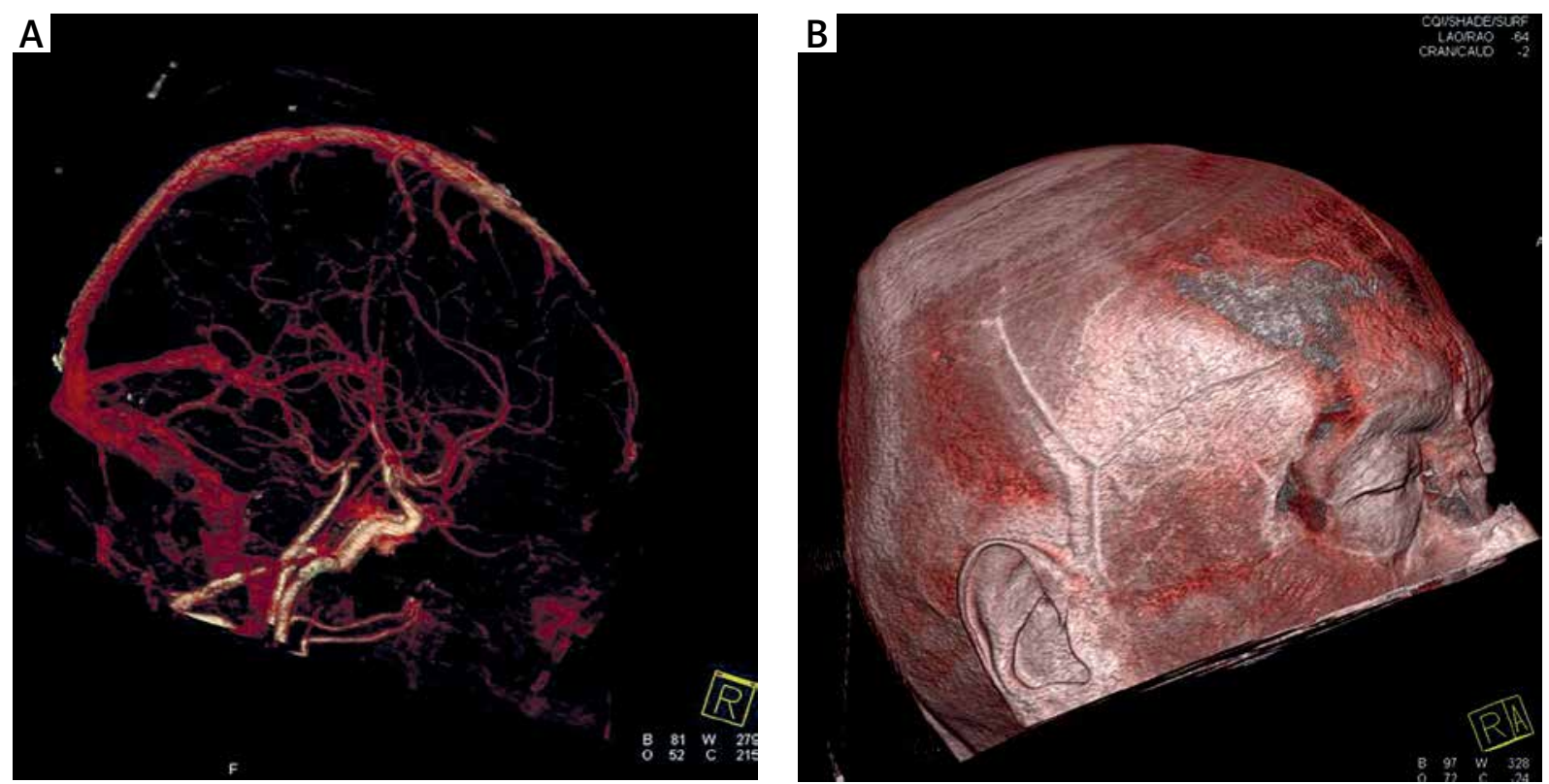

Figure 3. A - Angio-CT of the head revealed the absence of pathological changes in the wall of the right temporal artery. B - Angio-CT 3D reconstruction of the head without changes in the course of the right temporal artery

Also B-mode ultrasound presents the normal blood flow of the artery at this time (Figure 4).

This 77-year-old woman with a new temporal headache and increased ESR fits the GCA caused Horton's disease criteria established by ACR. Horton's disease in elderly patients should be still left for the differential diagnosis, especially after excluding other causes of headaches and despite an ESR of over $50 \mathrm{~mm} / \mathrm{h}[17,18]$. The ischemic features, such as jaw claudication or vision deficits were absent. In our case, initially the symptoms were combined with a recent dental procedure during which bacteremia and mechanical tissue damage could be triggers for pathological inflammatory mechanisms associated with Horton's disease. This confirms that GCA may appear with highly variable clinical forms and situations, making diagnosis difficult. An atypical presentation of the disease with the unusual clinical manifestation is being confirmed in the current literature, what reminds about the serious problem with underdiagnosis or inadequate management assessing the so-called "masked GCA" [19-21]. The authors of publications cited above specify the orofacial manifestations present with a variety of related clinical signs and symptoms as the most common clinical reasons for the delay of diagnosis or misdiagnosis of Horton's disease especially in older persons. Also in the presented patient, results of the rheumatoid factor and connective tissue diseases markers were all negative, but it is important to mention that in some older patients, polymyalgia rheumatica can coexist with giant-cell arteritis [22-25]. The temporal artery biopsy was not performed, but the typical clinical picture in-

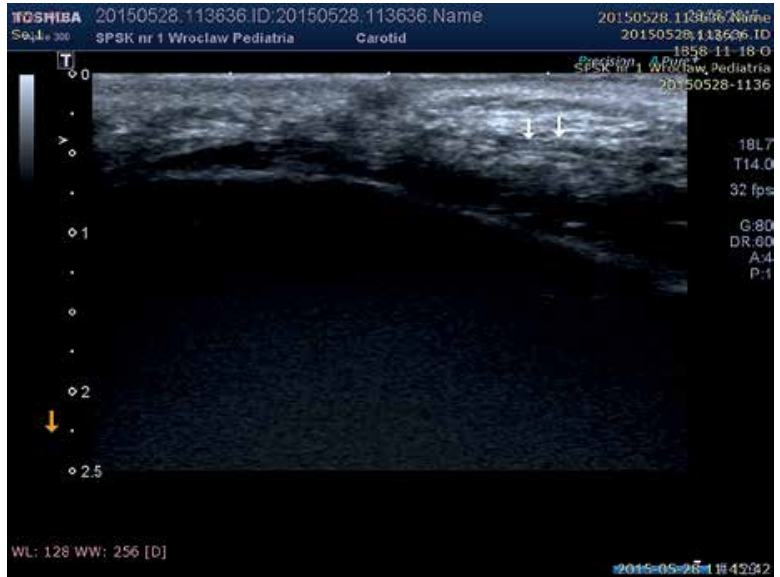

Figure 4. B-mode ultrasound presents the normal blood flow of the right carotid artery

cluding laboratory abnormalities and symptoms allowed us to make a certain diagnosis supported by a good therapeutic effect after corticosteroids (ex iuvantibus diagnosis). Besides, rapid effectiveness of corticosteroids is rather rarely seen in these cases as it takes $1-2$ years to get control of vasculitis in Horton's disease [26]. The absence of vascular changes in radiological examinations in the presented case indicate a mild course of vasculitis, which is rather rare and unusual in GCA. In the end, this case is yet another reminder that Horton's disease is still an important medical problem in elderly patients as well as it is present in clinical practice in which early diagnosis of GCA is of paramount importance. 


\section{Conflict of interest}

The authors declare no conflict of interest.

\section{References}

1. Horton BT, Magath BT, Brown GE. Arteritis of temporal vessels: report of 7 cases. Proc Stav Meet Mayo Clin 1937; 12: 548-53.

2. Boes CJ. Bayard Horton's clinicopathological description of giant cell (temporal) arteritis. Cephalalgia 2007; 27: 68-75.

3. Ward TN, Levin M. Headache in giant cell arteritis and other arteritides. Neurol Sci 2005; 26: 134-7.

4. Levin M, Ward TN. Horton's disease: past and present. Curr Pain Headache Rep 2005; 9: 259-63.

5. Cheema MR, Ismaeel SM. Temporal arteritis with erythrocyte sedimentation rate $<50 \mathrm{~mm} / \mathrm{h}$ : a clinical reminder. Clin Interv Aging 2016; 11: 185-8.

6. Galassi FM, Galassi S. A case of Horton's disease (with its potential neurological symptoms) depicted in a portrait by Andrea Mantegna. Neurol Sci 2016; 37: 147-8.

7. Frohman L, Wong AB, Matheos K, et al. New developments in giant cell arteritis. Surv Ophthalmol 2016; 61: 400-21.

8. Cantini F, Niccoli L, Nannini C, et al. Diagnosis and treatment of giant cell arteritis. Drugs Aging 2008; 25: 281-97.

9. Kale N, Eggenberger E. Diagnosis and management of giant cell arteritis: a review. Curr Opinion Ophthalmol 2010; 21: 417-22.

10. Croft AP, Thompson N, Duddy MJ, et al. Cranial ultrasound for the diagnosis of giant cell arteritis. A retrospective cohort study. J R Coll Physicians Edinb 2015; 45: 268-72.

11. Muratore F, Boiardi L, Cavazza A, et al. Correlations between histopathological findings and clinical manifestations in biopsy-proven giant cell arteritis. J Autoimmun 2016; 69: 94-101.

12. Hunder GG, Bloch DA, Michel BA, et al. The American College of Rheumatology 1990 criteria for the classification of giant cell arteritis. Arthritis Rheum 1990; 33: 1122-8.

13. Kötter I, Henes JC, Wagner AD, et al. Does glucocorticosteroid-resistant large-vessel vasculitis (giant cell arteritis and Takayasu arteritis) exist and how can remission be achieved? A critical review of the literature. Clin Exp Rheumatol 2012; 30: 114-29.

14. Kermani TA, Warrington KJ, Cuthbertson D, et al. Disease relapses among patients with giant cell arteritis: a prospective, longitudinal cohort study. J Rheumatol 2015; 42: 1213-7.

15. Jover JA, Hernandez-Garcia C, Morado IC. Combined treatment of giant-cell arteritis with methotrexate and prednisone. A randomized, double-blind, placebo-controlled trial. Ann Intern Med 2001; 134: 106-14.

16. Steel L, Khan A, Dasgupta B. Giant cell arteritis: beyond corticosteroids. Drugs Aging 2015; 32: 591-9.

17. Jhun P, Aguilera P, Shoenberger J, et al. Giant cell arteritis: read the fine print. Ann Emerg Med 2015; 65: 615-7.

18. Muller G, Devilliers H, Besancenot JF, Manckoundia P. Giant cell arteritis (Horton's disease) in very elderly patients aged 80 years and older: a study of 25 cases. Geriatr Gerontol Int 2016; 16: 679-85.

19. Blot M, Guépet H, Aubriot-Lorton MH, et al. An atypical case of giant cell arteritis (Horton's disease) associated with facial swelling, confusion, and pericarditis in an elderly woman. J Am Geriatr Soc 2010; 58: 2040-1.

20. Ferrari L, Preziosa P, Barcella V, et al. Subacute visual loss and bilateral fixed mydriasis: an atypical case of giant cell arteritis. Neurol Sci 2014; 35: 1309-10.
21. Hittinger M, Berlis A, Pfadenhauer K. Inflammatory pseudotumour orbitae (PTO): an atypical manifestation of giant cell arteritis. Clin Neuroradiol 2015; 25: 411-4.

22. Rodriguez-Valverde V, Sarabia JM, González-Gay MA, et al. Risk factors and predictive models of giant cell arteritis in polymyalgia rheumatica. Am J Med 1997; 102: 331-6.

23. Pujades-Rodriguez M, Duyx B, Thomas SL, et al. Associations between polymyalgia rheumatica and giant cell arteritis and 12 cardiovascular diseases. Heart 2016; 102: 383-9.

24. Panaszek B, Małolepszy J, Barg W. Polymyalgia rheumatica. Wiad Lek 1987; 40: 1620-4.

25. Schmidt J, Warrington KJ. Polymyalgia rheumatica and giant cell arteritis in older patients: diagnosis and pharmacological management. Drugs Aging 2011; 28: 651-66.

26. Hocevar A, Rotar Z, Jese R, et al. Do early diagnosis and glucocorticoid treatment decrease the risk of permanent visual loss and early relapses in giant cell arteritis: a prospective longitudinal study. Medicine (Baltimore) 2016; 95: e3210. 